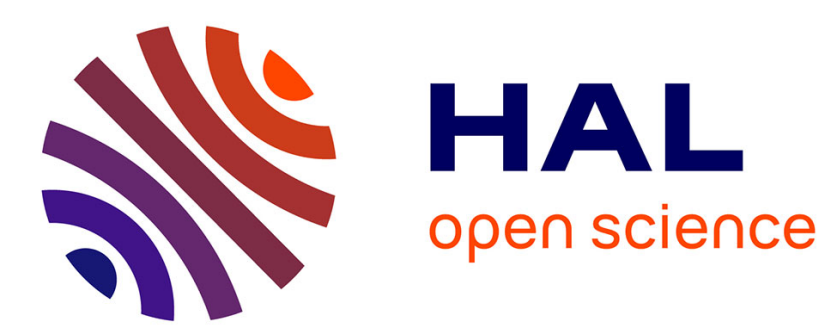

\title{
ELECTRON EXCITATION DATA FOR ALKALI-LIKE IONS
}

\author{
R. Henry
}

\section{To cite this version:}

R. Henry. ELECTRON EXCITATION DATA FOR ALKALI-LIKE IONS. Journal de Physique IV Proceedings, 1991, 01 (C1), pp.C1-57-C1-59. 10.1051/jp4:1991107 . jpa-00249745

\section{HAL Id: jpa-00249745 https://hal.science/jpa-00249745}

Submitted on 1 Jan 1991

HAL is a multi-disciplinary open access archive for the deposit and dissemination of scientific research documents, whether they are published or not. The documents may come from teaching and research institutions in France or abroad, or from public or private research centers.
L'archive ouverte pluridisciplinaire HAL, est destinée au dépôt et à la diffusion de documents scientifiques de niveau recherche, publiés ou non, émanant des établissements d'enseignement et de recherche français ou étrangers, des laboratoires publics ou privés. 


\section{ELECTRON EXCITATION DATA FOR ALKALI-LIKE IONS}

\section{R.J.W. HENRY}

Department of Physics, Auburn University, Auburn, Alabama 36849, U.S.A.

\section{1 - INTRODUCTION}

Since the review of data at the workshop in $1987 / 1 /$, research has proceeded on three aspects of excitation of alkali-like ions by electron impact: (a) direct integral cross sections; (b) direct angular distributions; and (c) indirect integral cross sections from inner she1l excitation contributions to ionization.

\section{2 - DIRECT INTEGRAL CROSS SECTIONS}

A notable discrepancy still exists between the latest theoretical predictions /2/ and experimental data /3/ for the $2 \mathrm{~s} \rightarrow 2 \mathrm{p}$ excitation cross section of BeII. Results in both a five-state $(2 \mathrm{~s}, 2 \mathrm{p}, 3 \mathrm{~s}, 3 \mathrm{p}, 3 \mathrm{~d})$ and nine-state $(5+\overline{4 s}, \overline{4 \mathrm{p}}, \overline{4 \mathrm{~d}}, \overline{4 \mathrm{f}})$ close coupling approximation including polarization effects are similar to previous calculations /4/ and give theoretical cross sections larger than measured ones by $18 \%$ (independent of energy). This is more than twice the quoted high confidence level (98\%) uncertainty attributed to the experimental data. For Na-like $\mathrm{Al}^{2+}$, Mitroy and Norcross /5/ used a five-state (3s,3p,3d,4s,4p) and nine-state $(5+\overline{4 d}, \overline{4 f}, \overline{5 s}, \overline{5 p})$ close coupling approximation including one- and two-body polarization potentials. They found that inclusion of core polarization effects caused a $10 \%$ decrease in the cross section. Their cross sections are within $10 \%$ for $3 s-3 p$ of those obtained by Dufton and Kingston $/ 6 /$ who used a five-state close coupling approximation and $10 \%$ was also the difference between $5 \mathrm{cc}$ and $9 \mathrm{cc}$ calculations for $3 \mathrm{~s}-3 \mathrm{p}$. However, for excitation of $3 \mathrm{~d}$, 4s and $4 \mathrm{p}$ levels from the $3 \mathrm{~s}$ level, the $9 \mathrm{cc}$ approximation gives cross sections $50 \%$ smaller than those obtained in a $5 \mathrm{cc}$ approximation. Mitroy and Norcross /5/ conclude that calculations are not converged for excitations which are not dominated by long range interactions (i.e. high partial waves).

Pindzola, Griffin, and Bottcher $/ 7 /$ examined K-like ions $\mathrm{Ca}^{+}, \mathrm{Sc}^{2+}, \mathrm{Ti}^{3+}, \mathrm{Cr}^{5+}$ and $\mathrm{Fe}^{7+}$. They found that agreement to $10 \%$ or better between close coupling and distorted wave approximation calculations for excitations among ground and low-lying excited states is first obtained for $\mathrm{Fe}^{7+}$. For $\mathrm{Ca}^{+}$, a unitarized distorted wave method brings significant improvement in cross section results for $4 \mathrm{~s} \rightarrow 4 \mathrm{p}$ and $3 \mathrm{~d} \rightarrow 4 \mathrm{p}$ over the normal non-unitarized distorted wave ones. For $\mathrm{Ca}^{+}$, Mitroy et al /8/ used a six-state (4s,3d,4p,5s,4d,5p) close coupling approximation and found that addition of core polarization effects caused a $20 \%$ decrease in the $4 \mathrm{~s}-3 \mathrm{~d}$ cross section over that obtained without polarization by Msezane./9/ This brought the calculation into good agreement with measurements of Taylor and Dunn /10/, although inclusion of cascade effects which contribute approximately $20 \%$ removes the agreement. Msezane $/ 9 /$ also points out the unusual situation for $\mathrm{Ca}^{+}$in that the $4 \mathrm{~s} \rightarrow 4 \mathrm{~d}$ excitation cross section is larger than the $4 s \rightarrow 3 d$ one probably due to a virtual double-dipole mechanism via the $4 \mathrm{p}$ intermediate level. 
For $\mathrm{Sr}^{+}$, Chidichimo /11/ made some calculations in three-state no exchange distorted wave, Coulomb Born, and Coulomb Bethe approximations. For $\mathrm{Ba}^{+}$, Peart, Underwood and Dolder /12/ made some very accurate measurements in the threshold to $30 \mathrm{eV}$ electron impact range and are now attempting to obtain similar data for $\mathrm{Ca}^{+}$.

\section{3 - DIRECT DIFFERENTIAL CROSS SECTIONS}

Differential cross sections for $1 \mathrm{~s}^{2} 2 \mathrm{~s} \rightarrow 1 \mathrm{~s} 2 \mathrm{~s}^{2}$ excitation of Li-like $\mathrm{Be}^{+}, \mathrm{B}^{2+}, \mathrm{C}^{3+}, \mathrm{N}^{4+}, \mathrm{O}^{5+}$ and $\mathrm{Ne}^{7+}$ have been calculated by Srivastava and Madison /13/ using a distorted wave approximation with exchange. For near threshold energies, they find that there is a minimum near $60^{\circ}$ and a peak in the backward direction. Contrary to expectations, the backward peak is not due to exchange; non-exchange calculations give angular distributions even more strongly peaked at back angles. For higher energies, the minimum disappears and the differential cross section become peaked in the forward direction.

New measurements underway in a merged beam electron energy loss experiment designed by G. Dunn (JILA) and colleagues should yield significant improvements in the data available to test theoretical models.

\section{4 - INNER SHELL EXCITATION-AUTOIONIZATION}

Significant advances have been made in the past two years in experimental technique for measurement of ionization cross sections. Data from the Giessen group of Müller et al /14/ is given in $\mathrm{Fig}$. I for $\mathrm{C}^{3+}$. It demonstrates the incredible accuracy and improvement in experimental data. Clearly shown are examples of resonance excitation auto double ionization represented by the excited complexes $1 s 2 s^{2} 2 p^{3} \mathrm{P}$ and $1 \mathrm{~s} 2 \mathrm{~s}_{2} \mathrm{p}^{2}{ }^{3} \mathrm{D}$, and resonance excitation double autoionization given by $1 s 2 \mathrm{~s}^{2}{ }^{2} \mathrm{~s}, \ldots, 1 \mathrm{~s} 2 \mathrm{~s} 2 \mathrm{p}^{2} \mathrm{p}^{\circ}$.

For Na-like $\mathrm{Fe}^{15+}$, calculations in close coupling and distorted wave approximations by Tayal and Henry /15/ and Griffin, Pindzola, and Bottcher /16/ agree within 10\%. The twelvestate close coupling calculation includes large numbers of bound terms of appropriate symmetry to account for the REDA process. The results are in fair agreement with crossedbeam measurements of Gregory et a1. /17/ More recent1y, Chen, Reed, and Moores /18/ have included 10000 autoionizing states and obtained excellent agreement with Gregory et al as is seen in Fig. 2 .

For $\mathrm{K}-1$ ike $\mathrm{Ca}^{+}$, Pindzola, Bottcher and Griffin /19/ noted that $3 \mathrm{p} \rightarrow 3 \mathrm{~d}$ inner she11 excitation cross sections have considerable LS-term dependent effects. An unresolved mystery is the lack of observed structure in the ionization cross section obtained by Peart and Dolder /20/. Calculations yield lots of structure due to inner shell excitation and subsequent autoionization but no consistency as to the position of the structure.

\section{ACKNOWLEDGEMENTS}

Research was supported in part by the U.S. Department of Energy, Division of Chemica1 Sciences. 


\section{REFERENCES}

/1/ R.J.W. Henry, in "Atomic Data Workshop: Assessment of data for photo-ionization and for electron impact excitation of atomic ions" (1988) 128, edited by W. Eissner and A.E. Kingston.

/2/ J. Mitroy and D.W. Norcross, Phys. Rev. A 37, (1988) 3755.

/3/ P.O. Taylor, R.A. Phaneuf, and G.H. Dunn, Phys. Rev. A22, (1980) 435.

14/ M.A. Hayes, D.W. Norcross, J.B. Mann and W.D. Robb, J. Phys. B11, (1977) L429;

R.J.W. Henry, W.L. vanWyngaarden, and J.J. Matese, Phys. Rev. A17, (1978) 798 ;

F.A. Parpia, D.W. Norcross, and F.J. da Paixao, Phys. Rev. A34, (1986) 4777.

/5/ J. Mitroy and D.W. Norcross, Phys. Rev. A39, (1989) 537.

/6/ P.L. Dufton and A.E. Kingston, J. Phys. B20, (1987) 3899.

/7/ M.S. Pindzola, D.C. Griffin, C. Bottcher, Phys. Rev. A39, (1989) 3899.

/8/ J. Mitroy, D.C. Griffin, D.W. Norcross, and M.S. Pindzola, Phys. Rev. A38, (1988) 3339.

/9/ A.Z. Msezane, J. Phys. B21, (1988) L61.

/10/ P.O. Taylor and G.H. Dunn, Phys. Rev. A8, (1973) 2304.

/11/ M.C. Childichimo, Phys. Rev. A38, (1988) 6107.

/12/ B. Peart, J.R.A. Underwood and K. Dolder, J. Phys. B22, (1989) 1679.

/13/ R. Srivastava and D.H. Madison, Phys. Rev. A38, (1988) 5419.

/14/ A. Müller, G. Hoffman, K. Tinschert, and E. Salzborn, Phys. Rev. Letts. 61, (1988) 1352.

/15/ S.S. Tayal and R.J.W. Henry, Phys. Rev. A39, (1989) 3890.

/16/ D.C. Griffin, M.S. Pindzola, and C. Bottcher, Phys. Rev. A36, (1987) 3642.

/17/ D.C. Gregory, L.J. Wang, F.W. Meyer, and K. Rinn, Phys. Rev. A35, (1987) 3256.

/18/ M.H. Chen, K.J. Reed, and D.L. Moores, private communication (1989).

/19/ M.S. Pindzola, C. Bottcher, and D.C. Griffin, J. Phys. B20, (1987) 3535.

/20/ B. Peart and K.T. Dolder, J. Phys. Bㅇ, (1975) 56.

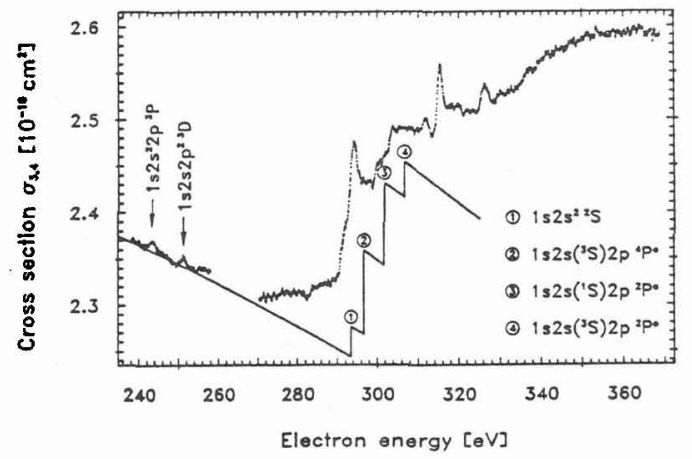

Fig. 1

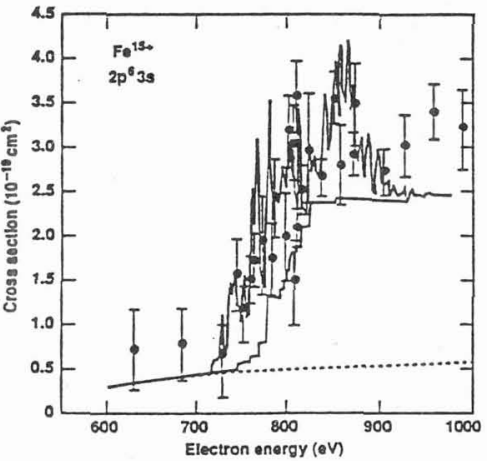

Fig. 2 